\title{
Laparoscopic Diagnosis and Excision of Meckel's Diverticulum
}

\author{
By Daniel H. Teitelbaum, Theodore Z. Polley, Jr, and Farouck Obeid \\ Ann Arbor, Michigan and Detroit, Michigan
}

\begin{abstract}
- Meckel's diverticulum is one of the primary concerns in the differential diagnosis of the pediatric patient with massive, acute gastrointestinal bleeding, intussusception, or abdominal pain of uncertain cause. The hospital course of two children with Meckel's diverticulum, successfully treated by laparoscopic excision, is presented, along with details of the operative procedure. Both patients recovered from the procedure without incident and were discharged at 24 and 48 hours after surgery. The authors believe a laparoscopic approach is safe and effective in the diagnosis and treatment of Meckel's diverticulum.

Copyright 1994 by W.B. Saunders Company
\end{abstract}

INDEX WORDS: Meckel's diverticulum, laparoscopy.

$\mathbf{M}$ ECKEL'S DIVERTICULUM (MD) may present with a wide variety of gastrointestinal complaints in the pediatric patient, including acute, lower gastrointestinal bleeding, intussusception, and abdominal pain of elusive cause. ${ }^{1}$ Conventional diagnosis consists of a technetium $99 \mathrm{~m}$ scintiscan; however, occasionally exploratory laparotomy is required. ${ }^{2}$ We used a laparoscopic approach in two patients to confirm the diagnosis of MD as well as to excise the diverticulum. These cases are presented, and the technical details of the procedure are described.

\section{CASE REPORTS}

\section{Patient 1}

A 15-year-old boy presented to the emergency room with the sudden onset of painless rectal bleeding, which stopped spontaneously. His hemodynamic condition remained stable, and he was admitted for evaluation. Results of a Meckel's scan, barium enema, and upper endoscopic studies were negative. Another Mcckel's scan was performed, with the addition of pentagastrin stimulation, and showed evidence of an MD in the midportion of the abdomen. The child underwent laparoscopic surgery for excision of the MD. A standard laparoscopic approach was employed, using a $10-\mathrm{mm}$ intraumbilical incision for the video camera and two additional lower abdominal incisions (right, $10 \mathrm{~mm}$; left, $12 \mathrm{~mm}$ ) for access of forceps and the stapling device, respectively. The ileocecal region was identified, and the small bowel was followed in a retrograde fashion using grasping forceps until the MD was found. Careful inspection of the small intestine was performed to confirm the exact orientation of the MD and afferent and efferent limbs. With the assistant holding traction on the tip of the diverticulum, curved dissecting forceps were used to isolate the arterial supply. The artery was ligated with the application of two surgical clips (Fig 1). A Multi-fire Endo-GIA 30 stapling device (US Surgical Corporation. Norwalk, (T) was then used to resect the diverticulum. The thickness of the base of the diverticulum was initially measured with a calibrating device. followed by the application of the stapler in an oblique fashion (Fig 2). Two firings of the stapler were needed in this case hecause the base was rather broad. Inspection confirmed hemostasis, and a laparoscopic appendectomy was subsequently performed using previously described techniques. ${ }^{3}$ Before terminating the procedure, the diverticulum was opened and complete resection of all gastric mucosal tissue was grossly confirmed. Postoperatively the patient did well. He was started on clear liquids the following day and discharged within 48 hours. $\mathrm{He}$ resumed full activity, including playing football, within 2 weeks of the operation.

\section{Patient 2}

An obese 9-year-old girl presented with a 3-week history of severe intermittent abdominal pain, with associated nausea and vomiting. There was no associated weight loss or fever, and her abdominal examination was normal. On two separate admissions, she underwent an extensive workup to determine the cause of the pain. This workup included an upper gastrointestinal series with small bowel follow through, barium enema, intravenous pyelogram, abdominal ultrasound, and abdominal computerized axial tomography; all the results were negative. The result of a pentagastrin-stimulated Meckel's scan was also negative. Stool cultures, sent on two occasions, had no significant pathogens, and laboratory values were all noncontributory. Because of persistent pain and excessive scholastic absenteeism, a diagnostic laparoscopy was performed. During exploration, an MD was identified, which was excised with the technique described above. A laparoscopic appendectomy was also performed. The pathological examination showed a $3-\mathrm{cm}$ Meckel's diverticulum with no ectopic mucosa. The patient did well and was discharged the next morning. She resumed normal activities within several days of the procedure and remains asymptomatic.

\section{DISCUSSION}

MD can present with a variety of clinical manifestations, including abdominal pain, gastrointestinal bleeding, intussusception, and volvulus of the small bowel. The diagnosis of MD can be elusive. Although radionucleotide studies have been a mainstay of diagnosis, only 55\% of MD have ectopic gastric mucosa detectable by a technetium $99 \mathrm{~m}$ scintiscan. ${ }^{4,5}$ The laparoscopic approach may be useful to diagnose MD. Use of diagnostic laparoscopy in the pediatric patient has been described frequently. Laparoscopy has been successful particularly in the evaluation of cases of possible appendicitis as well as those of nonpalpable

From the Section of Pediatric Surgery, Deparment of Surgery, University of Michigan Medical School and C.S. Mott Children's Hospital, Ann Arbor, MI, and the Department of Surger, Henny Ford Hospital, Detroit, $M$ I.

Date accepted: April 13, 1993.

Address reprint requests to Daniel $H$. Teitelbaum, MD, Section of Pediatric Surgery, University of Michigan Hospitals, Women's L2110, Box 0245. Ann Arbor, MI 48109.

Copyright 11994 by W.B. Saunders Company

$0022-3468 / 94 / 2904-0005 \$ 03.00 / 0$ 


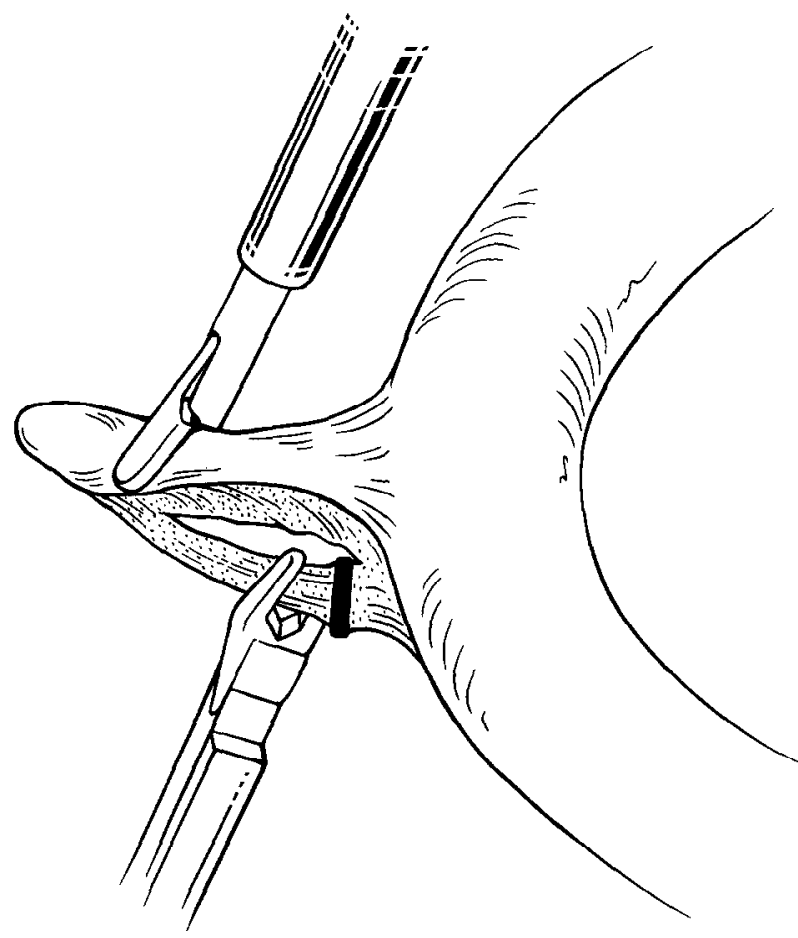

Fig 1. Arterial supply to the diverticulum is ligated with serial placement of clips and subsequently divided with laparoscopic scissors. Note the traction held on the tip of the diverticulum during the ligation and division.

testicles. ${ }^{6,7}$ More recently, a laparoscopic approach has been applied to a variety of pediatric surgical procedures including cholecystectomy, appendectomy, and detorsion of ovarian torsion. ${ }^{3,8,9}$ In our two cases, laparoscopy was used to diagnose as well as treat MD, with excellent results.

Only one previous case ${ }^{10}$ of MD involving laparoscopy was found during a review of the literature. However, in this case the MD was merely identified by the laparoscope, and the divcrticulum along with adjacent bowel was pulled out of the abdominal cavity and excised extracorporially. In our patients, the MD was completely excised using laparoscopic techniques.

The laparoscopic approach used for our two patients offers several benefits, including an improved ability to diagnose MD, as seen with our second patient. The laparoscope allowed us to inspect the abdomen for other pathology, with the least amount of invasiveness. The hospital stay is significantly shorter and return to physical activities is much quicker than with the conventional open technique. An additional advantage to the patient is the marked reduction in postoperative pain. No narcotics were necessary for our patients after the first postoperative day.

One technical aspect of the laparoscopic procedure should be emphasized. Caution should be taken during the initial exploration of the abdomen and while examining the bowel for MD. A broad-based
MD may be overlooked unless a great deal of care is given to inspecting the bowel in an orderly, retrograde fashion. Additional technical aspects that should be emphasized in such cases include a detailed examination of the MD and its relation to the intestine so that the maximal amount of tissue can be excised without narrowing the bowel lumen. A maneuver we used to avoid intestinal narrowing was to fire the Endo-GIA stapler in an oblique fashion across the antimesenteric surface. Identification and control of the arterial supply is essential, and adequate hemostasis can be achieved using the automatic clip appliers.

An appendectomy was performed in both patients at the end of the procedure. In the first, it was entirely elective; in the second, it was performed to eliminate all possible causes of abdominal pain. The operative time for each case was approximately 2 hours. Despite this increased operative time, the postoperative hospitalization period was brief ( 24 to 48 hours) and resumption of activities was extremely quick (1 to 2 weeks).

In summary, we describe a laparoscopic approach in two cases of MD. In one, the laparoscope was used to diagnose the MD. In both cases, the MD was completely excised using the laparoscopic technique. This technique has proven useful in the diagnosis of MD as well as its treatment.

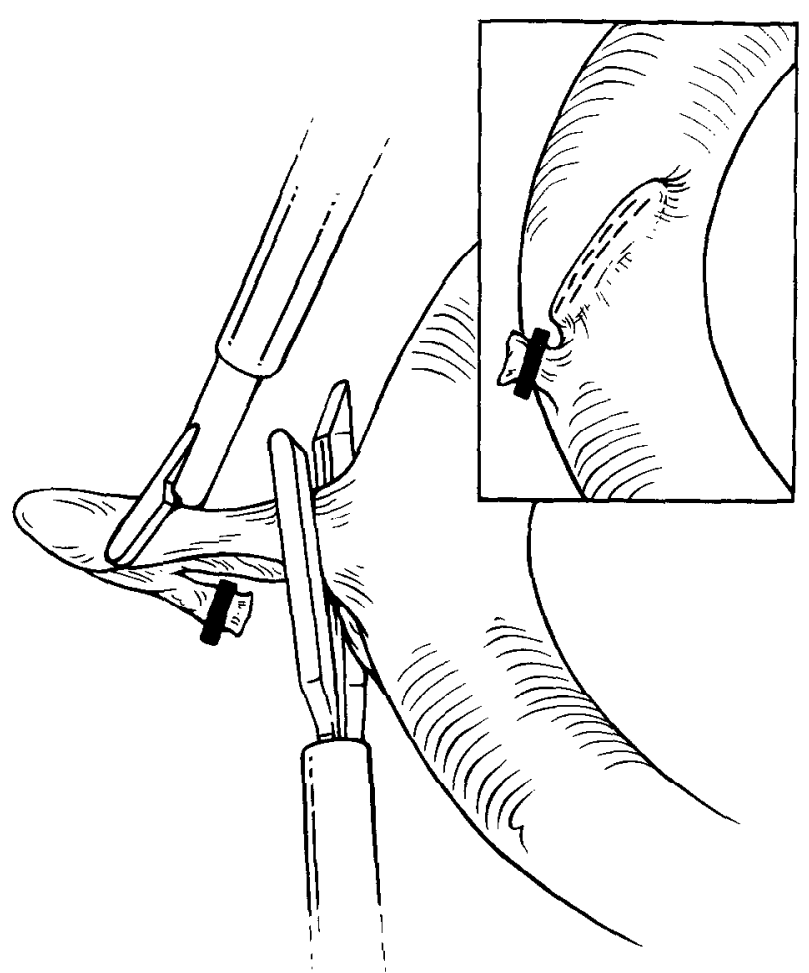

Fig 2. Diverticulectomy is performed with the Endo-GIA. Note the oblique angle of transection and the proximity to the intestinal lumen (inset). 


\section{REFERENCES}

1. Soltero MJ, Bill AH: The natural history of Meckel's diverticulum and its relation to incidental removal. Am J Surg 132:168-173, 1976

2. Treves S, Grand RJ, Eraklis AJ: Pentagastrin stimulation of technetium-99m uptake by ectopic gastric mucosa in a Meckel's diverticulum. Radiology 128:711-712, 1978

3. Scott-Conner CEH, Hall TJ, Anglin BL, et al: Laparoscopic appendectomy: Initial experience in a teaching program. Ann Surg 215:660-668, 1992

4. Berquist TH, Nolan NG, Stephens DH, et al: Specificity of

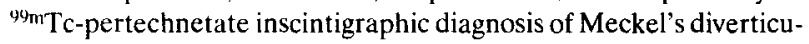
lum: Review of 100 cases. J Nucl Med 17:465-469, 1976

5. Rosenthall L, Henry JN, Murphy DA: Radiopertechnetate imaging of the Meckel's diverticulum. Radiology 105:371-373, 1972
6. Leape LL, Ramenofshky ML: Laparoscopy for questionable appendicitis: Can it reduce the negative appendectomy rate? Ann Surg 191:410-413, 1980

7. Kleinhaus S, Hein K, Sheran M, et al: Laparoscopy for diagnosis and treatment of abdominal pain in adolescent girls. Arch Surg 112:1178-1179, 1977

8. Sigman HH, Laberge J, Croitoru D, et al: Laparoscopic cholecystectomy: A treatment option for gallbladder disease in children. J Pediatr Surg 26:1181-1183, 1991

9. Shalev E, Mann S, Romano S, et al: Laparoscopic detorsion of adnexa in childhood: A case report. J Pediatr Surg 26:1193-1194. 1991

10. Attwood SEA, McGrath J, Hill ADK, et al: Laparoscopic approach to Meckel's diverticulotomy. Br J Surg 79:211. 1992 